Original Research

\title{
Genetic Diversity of Lusitano Horse in Brazil Using Pedigree Information
}

\author{
Ricardo António da Silva Faria a, *, António Pedro Andrade Vicente c, d, \\ Rute Isabel Duarte Guedes dos Santos e, f, Amanda Marchi Maiorano a', \\ Rogério Abdallah Curi ${ }^{\mathrm{b}}$, Luis Artur Loyola Chardulo ${ }^{\mathrm{b}}$, \\ Josineudson Augusto II Vasconcelos Silva ${ }^{\text {b }}$ \\ ${ }^{a}$ Universidade Estadual Paulista (Unesp), Faculdade de Ciências Agrárias e Veterinárias, CEP 14.884-900, Jaboticabal, São Paulo, Brazil \\ ${ }^{\mathrm{b}}$ Universidade Estadual Paulista (Unesp), Faculdade de Medicina Veterinária e Zootecnia, CEP 18.618-307, Botucatu, São Paulo, Brasil \\ c Escola Superior Agrária do Instituto Politécnico de Santarém, Apartado 310, 2001-904 Santarém, Portugal \\ d CIISA - Faculdade de Medicina Veterinária, Universidade de Lisboa, 1300-477 Lisboa, Portugal \\ e Instituto Politécnico de Portalegre - Escola Superior Agrária de Elvas, 7350-903 Elvas, Portugal \\ ${ }^{\mathrm{f}}$ VALORIZA - Centro de Investigação para a Valorização de Recursos Endógenos, 7300- 555 Portalegre, Portugal
}

\section{A R T I C L E I N F O}

\section{Article history:}

Received 21 March 2018

Received in revised form

12 July 2018

Accepted 14 July 2018

Available online 3 August 2018

\section{Keywords:}

Ancestors

Demographic characterization

Effective population size

Founders

Inbreeding

\begin{abstract}
A B S T R A C T
This study aimed to evaluate population parameters and to describe the genetic diversity of the Lusitano breed in Brazil using pedigree data. Two populations were evaluated: total population (TP) containing 18,922 animals, and reference population (RP) composed of a part of TP containing 8,329 animals, representing the last generation. The generation interval (10.1 \pm 5.1 years) was in the range for horse populations. Pedigree completeness in RP shows almost $100 \%$ filling in the three most recent generations, indicating improvement in the pedigree data and accuracy of the results, and the inbreeding coefficient (4.46\%) and average relatedness (5.97\%) for RP, indicating control on the part of breeders. The effective population size was 89 (TP) and 90 (RP). The effective number of founders $\left(f_{e}\right)$ were 33 and 29 , effective number of ancestors $\left(f_{a}\right)$ were 30 and 26, and effective number of founder genomes $\left(f_{g}\right)$ were 19 and 15 for TP and RP, respectively, indicating a reduction of genetic variability in the last generations. The total number of ancestors that explains $100 \%$ of the genetic diversity in the Lusitano breed in Brazil was 427 (TP) and 341 (RP). The reproductive parameters, probabilities of gene origin showing loss of variability in the last generations, and the genetic contributions of ancestors suggest the need to monitor genetic diversity over time in breeding programs to allow control of the next generations and to increase their variability.
\end{abstract}

(C) 2018 Elsevier Inc. All rights reserved.

\section{Introduction}

The Puro Sangue Lusitano (PSL), also known as the Lusitano horse, represents a breed with a rich and ancient history, originated in southern Portugal on the Iberian Peninsula. Its evolution is essentially

\footnotetext{
Animal welfare/ethical statement: No animal was used in the present research "Genetic diversity of Lusitano horse in Brazil using pedigree information"; only the pedigree data of the animals were used.

Conflict of interest statement: The authors wish to confirm that there are no known conflicts of interest associated with this publication and there has been no significant financial support for this work that could have influenced its outcome.

* Corresponding author at: Ricardo António da Silva Faria, FMVZ - Unesp, DMNA Fazenda Experimental Lageado, Rua José Barbosa de Barros, n 1780 CEP: 18.618307, Botucatu, SP, Brasil.

E-mail address: fariasky@gmail.com (R.A. da Silva Faria).
}

due to their use for working cattle and cutting bulls [1]. Although records date back to 1824 , the studbook of the Lusitano breed was officially established in 1967 [2], a time when the main Iberian breeds, Portuguese and Spanish, were separated and received the denomination PSL in Portugal and Pura Raza Española in Spain.

The main studbook of the Lusitano breed is managed in Portugal by the Portuguese Lusitano Horse Breeder Association (APSL in the Portuguese acronym), which has the largest number of birth records of the breed in the world [2]. Brazil is the country with the second largest number of animal records of this breed. This statistic was determined after the reciprocity partnership between APSL and the Brazilian Lusitano Horse Breeder Association (ABPSL in the Portuguese acronym) was established in 1991. This agreement permitted all Lusitano horses registered in the Brazilian studbook to be equally registered in the Portuguese studbook, which contains the birth records of all countries. 
Studies investigating population parameters of the Lusitano breed have been conducted only with data from the APSL studbook (Portugal) for all Lusitano horses registered in the world [2,3]. Thus, data on the population statistics and genetic diversity of the Lusitano breed in Brazil are lacking.

Parameters such as pedigree completeness [4], generation interval (GI), inbreeding coefficient [5], and probability of gene origin [6] are important to design strategies for the selection and improvement of animals. The data generated permit to verify genetic diversity and its changes over time [7]. The complete or partial results of genetic diversity and population parameters are reported in the literature for various horse breeds, including Andalusian [8], Holstein [9], Paint Horse [10], Hanoverian [11], Spanish Arab Horse [12], Lipizzaner [13], and Old Kladruber [14]. In Brazil, studies were conducted on the Pantaneiro [15], Mangalarga [16], Campolina [17], Brazilian Sport Horse [18], and Quarter Horse [19] breeds.

This study aimed to evaluate the population parameters of the Lusitano horse in Brazil to observe the genetic diversity and to contribute to the knowledge and development of this breed in Brazil and to compare our results with the ones obtained by different authors for the worldwide population [2,3], providing the information necessary to implement a breeding program of the breed in Brazil.

\section{Materials and Methods}

\subsection{Data and Computer Programs}

The pedigree file of the Lusitano breed containing information about the animal's name, sire and dam, sex, date of birth, and origin was provided by ABPSL. Animals born and registered in Brazil between 1912 and 2012 were considered and made up the total population (TP) of 18,922 animals (48.1\% males, stallions and geldings) and the reference population (RP) consisting of 8,329 animals (51.0\% males, stallions and geldings), corresponding to the birth records from 2003 to 2012. RP was used as the reference of the active population, representing the last generation, which was equal to one mean GI (10.1 years) and contained animals (stallions and mares) that potentially could transmit their genes to the next generation.

Data preparation and statistical analysis were performed with the MEAN and FREQ procedures of the SAS program [20]. The population and reproductive parameters, probability of gene origin, and genetic diversity were obtained with the ENDOG V4.8 program [21].

\subsection{Reproductive Parameters and Generation Interval}

The existence of imported animals registered in the studbook of ABPSL permitted to observe their use as breeding stock and to compare it with that of sires and dams born in Brazil. The coefficients of variation for the mean number of offspring, age at first and last progeny, and time in reproduction obtained for stallions and mares explain the high standard deviation between the different parameters analyzed. These parameters were not calculated for RP because of the small number of imported breeding animals during this period and because the population is still in reproduction.

The GI was obtained based on the mean age of the parents at the birth of offspring that reproduced [22] and was calculated for the four different paths of selection: father-son, father-daughter, mother-son, and mother-daughter, and total parent-offspring.

\subsection{Quality of Pedigree Data}

The quality of the information in the ABPSL studbook is reported in two ways: (1) pedigree completeness summarizes the proportion of known ancestors in each ascending generation per descendant and was calculated as proposed by MacCluer et al [4], in which ancestors without progenitors in the pedigree were considered founders [21]; (2) based on the mean number of generation equivalents (GE), computed over the sum of all known ancestors by calculating $(1 / 2)^{n}$, where $n$ is the number of generations between the animal and each known ancestor [7].

\subsection{Parameters Related to the Inbreeding Coefficient}

The inbreeding coefficient (F) defines the probability that an individual has two identical alleles by descent and was calculated using the algorithm proposed by Meuwissen and Luo [23].

The average relatedness (AR) coefficient of each animal was described by Gutiérrez and Goyache [21] as the representation of a given animal in the pedigree and was obtained based on the probability that a randomly selected allele of the population belongs to a given animal.

The increase in inbreeding $(\Delta \mathrm{F})$ for each generation was obtained as follows:

$\Delta \mathrm{F}=\left(\mathrm{F}_{\mathrm{t}}-F_{t-1}\right) /\left(1-F_{t-1}\right)$

where $F_{t}$ and $F_{t-1}$ are the average inbreeding in generations $t$ and $t-1$, respectively.

According to Falconer and Mackay [24], the effective size of a population $\left(\mathrm{N}_{\mathrm{e}}\right)$ is defined as the number of individuals of a population with a nonideal structure that would give origin to a certain rate of consanguinity if its structure were ideal (e.g., equal number of males and females, absence of selection, random matings, etc.). Using $\Delta \mathrm{F}, \mathrm{N}_{\mathrm{e}}$ was estimated considering $\mathrm{N}_{\mathrm{e}}=1 / 2 \Delta \mathrm{F}$, which represents the number of animals that equally contribute to the next generation and that would promote a similar increase in inbreeding in the population studied [21]. In addition, $\mathrm{N}_{\mathrm{e}}$ was also calculated based on the individual increase in inbreeding as suggested by Gutiérrez et al [25] and was used for the calculation of genetic drift.

\subsection{Probability of Gene Origin and Genetic Drift}

The effective number of founders $\left(f_{e}\right)$ is obtained by measuring the contributions of the most influential founders. Lacy [26] defines $f_{e}$ as the expected number of founders that contribute equally and produce the same genetic diversity in the population studied. This parameter was calculated using the formula

$f_{e}=1 / \sum_{k=1}^{f} q_{k}^{2}$

where $q_{k}$ is the probability of gene origin of founder $k$.

The effective number of ancestors $\left(f_{a}\right)$ represents the minimum number of ancestors (founders or not) necessary to explain the full genetic diversity of the population [6]. This parameter was calculated as

$f_{a}=1 / \sum_{j=1}^{f} p_{j}^{2}$

where $p_{j}$ is the marginal contribution of ancestor $j$. The marginal contribution is the additional genetic contribution made by an ancestor that was not explained by another previously chosen ancestor [6]. 
The effective number of founder genomes $\left(f_{g}\right)$ is defined as the number of sires and dams that contribute equally to the population structure and produce identical genetic diversity without the loss of alleles [27]. This parameter was estimated as proposed by Caballero and Toro [28] using the formula

$f_{g}=1 / 2 C$

where $C$ is the average coancestry between individuals of the population.

Genetic drift is the random change in allele frequencies in a population, which occurs at a higher intensity when the population undergoes a drastic reduction in its effective size [24]. According to Sørensen et al [29], a ratio of $\mathrm{f}_{\mathrm{e}} / \mathrm{N}_{\mathrm{e}}>0.5$ in a population indicates the occurrence of changes in genetic drift. One approach to evaluate genetic drift is the observation of bottleneck effects. The $\mathrm{f}_{\mathrm{e}} / \mathrm{f}_{\mathrm{a}}$ ratio should be close to 1 if important bottlenecks have not occurred in the population [6]. Stabilization of genetic drift in a population can be observed when $f_{e}$ is close to $N_{e} / 2$, suggesting a greater representation of founders [28].

\subsection{Genetic Conservation Index}

The number of founders represented in the contributions received by an individual and the balance between them were evaluated by computing the genetic conservation index (GCI) of all animals [30]. It is supposed that higher indices correspond to animals with a more balanced representation from a large number of founders, that is, greater genetic conservation of the breed. The GCI was computed for each animal using the formula

$G C I=1 / \sum P_{i}^{2}$

where $P_{i}^{2}$ is the proportion of genes of founder animal $i$ in the pedigree [21]. The mean of the populations was then calculated.

\section{Results}

\subsection{Data Analysis and Distribution of Birth Records}

In TP, 87.3\% of the animals were born in Brazil after 1967 and $4.0 \%$ were imported. The remaining animals are ancestors of both origins, which are registered only as parents in the database of ABPSL. In RP, 99.6\% of the animals studied were born in Brazil and the remaining $0.4 \%$ are derived from imported animals and ancestors.

The first birth registered by ABPSL and recognized by APSL was the female Azambuja in 1967 and the first male was Zapata in 1969, both half-sibs of the mare Zaza. Between 1967 and 1985, the births of only 305 animals were recorded (Fig. 1). A constant increase was observed after 1986, and the number of registered births per year reached three digits for the first time. Stabilization of the growth trend occurred in 2002, with reduced oscillations (approximately $5 \%$ ) in the following 8 years. The largest number of registered births was observed in 2006 (966 animals). A marked decline in the number of births was seen in the last 3 years (2010-2012) of the study (Fig. 1).

Births were observed in all months but there was wide oscillation. In TP, only $4.6 \%$ of births occurred in the ideal month (July). The months with the largest number of births were October (16.5\%), September (15.7\%), and November (15.3\%). The first, second, and last quarter of the year concentrated $17 \%, 5 \%$, and $45 \%$ of births, respectively.

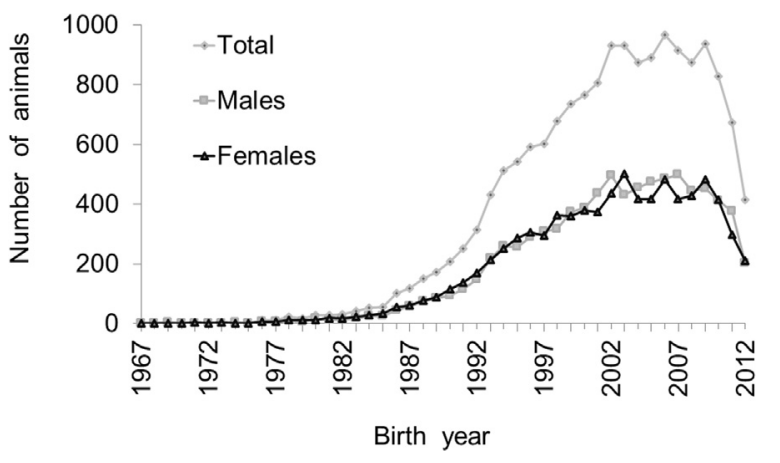

Fig. 1. Number of births (males, females, and all animals) registered in the studbook of the Lusitano horse breed in Brazil by year of birth.

\subsection{Reproductive Parameters and Generation Interval}

In the database, there were 16,511 (50.4\% males, stallions and geldings) Lusitano horses born in Brazil (national) and 781 (32.9\% males, stallions and geldings) imported animals (e.g., Portugal and Mexico). Of the 8,319 national males, only $10.1 \%$ had offspring, whereas 257 (72.2\%) of the imported males were used as stallions. Of the 8,192 national females, $37.7 \%$ had offspring and $96.2 \%$ of the 524 imported females were used as mares.

All animals born in Brazil (16,511) were sired by 1,115 stallions; $57.5 \%$ of the offspring had a sire of Brazilian origin, $40.8 \%$ had an imported sire, $1.6 \%$ were obtained by artificial insemination, and the sire was unknown in $0.1 \%$. Among the 3,594 breeding mares that contributed to the Brazilian population, $77.2 \%$ of the offspring had a dam of Brazilian origin, $22.6 \%$ had an imported dam, $0.1 \%$ were obtained by embryo transfer, and the dam was unknown in the remaining $0.1 \%$.

There was a greater utilization of females, with a ratio of 3.1 mares $(4,644)$ per stallion $(1,507)$. This ratio was 4.5 mares per stallion (210 stallions and 946 mares) in the most productive year (2006). The mean number of offspring (Table 1) considering only breeding animals was 12.3 and 4.0 for stallions and mares, respectively. Considerable differences were observed in the maximum number of offspring, with stallion Afiançado de Flandes having 419 offspring registered, the largest number for the whole breed worldwide.

The mean age of stallions at the birth of their first progeny was 7.0 years and mares had their first foal at 5.9 years (Table 1 ). The mean age at the birth of the last progeny was similar in stallions and mares, with a difference of 0.2 years (Table 1 ). The difference

Table 1

Summary descriptive statistics of reproductive parameters of Lusitano stallions and mares in Brazil.

\begin{tabular}{|c|c|c|}
\hline \multirow[t]{2}{*}{ Item } & \multicolumn{2}{|c|}{ Total Population } \\
\hline & Stallion & Mare \\
\hline \multicolumn{3}{|l|}{ Offspring } \\
\hline Total $(\mathrm{n})$ & $18,515^{\mathrm{a}}$ & $18,436^{\mathrm{b}}$ \\
\hline Mean \pm SD $(n)$ & $12.3 \pm 24.5$ & $4.0 \pm 3.4$ \\
\hline $\operatorname{Maximum}(\mathrm{n})$ & 419 & 20 \\
\hline \multicolumn{3}{|l|}{ Stallions/mares } \\
\hline Total (n) & 1,507 & 4,644 \\
\hline Age at first progeny (years) & $7.0 \pm 3.8$ & $5.9 \pm 3.1$ \\
\hline Age at last progeny (years) ${ }^{c}$ & $10.7 \pm 5.7$ & $10.5 \pm 5.3$ \\
\hline
\end{tabular}

Abbreviations: $\mathrm{N}$, number of the respective observation; SD, standard deviation.

a Offspring with known father (independently of knowing the mothers).

b Offspring with known mother (independently of knowing the father).

c Only calculated for animals with two or more offspring. 
Table 2

Generation interval (in years) for the four paths of selection between parents and offspring that reproduced for Lusitano horses in Brazil.

\begin{tabular}{lrrrr}
\hline Path of selection & \multicolumn{2}{c}{ Total Population } & \multicolumn{2}{c}{ Reference Population } \\
& $\mathrm{n}$ & \multicolumn{1}{c}{ Mean $\pm \mathrm{SD}$} & \multicolumn{1}{c}{$\mathrm{n}$} & \multicolumn{1}{c}{ Mean \pm SD } \\
Father-son & 1,393 & $10.9 \pm 6.0$ & 146 & $9.4 \pm 4.7$ \\
Father-daughter & 4,409 & $10.8 \pm 5.5$ & 679 & $11.4 \pm 6.0$ \\
Mother-son & 1,374 & $9.5 \pm 4.5$ & 144 & $10.2 \pm 4.7$ \\
Mother-daughter & 4,350 & $9.2 \pm 4.5$ & 679 & $9.6 \pm 4.4$ \\
Overall mean & 11,526 & $10.1 \pm 5.1$ & 1,648 & $10.2 \pm 5.0$ \\
\hline
\end{tabular}

Abbreviations: $n$, number of observations; SD standard deviation.

between the birth of the first and last offspring, indicating the time in reproduction, was $3.7 \pm 5.0$ years for stallions and $4.6 \pm 5.1$ years for mares.

High standard deviations were observed for all reproductive parameters analyzed (Table 1). A standard deviation higher than the mean was found for the number of offspring per stallion, which was almost the double of the mean value. The coefficients of variations indicated a high level of dispersion, which were 199.1\% (number of offspring), 54.3\% (age at first progeny), 53.3\% (age at last progeny), and $135.1 \%$ (time in reproduction) for stallions, and $85.0 \%$ (number of offspring), 52.5\% (age at first progeny), 50.5\% (age at last progeny), and $110.9 \%$ (time in reproduction) for mares.

The overall mean GI was $10.1 \pm 5.1$ and $10.2 \pm 5.0$ years for TP and RP, respectively (Table 2). When the four paths of selection were considered, shorter GIs were observed for the motheroffspring paths in TP. The same trend was not found in RP, with longer and shorter GIs between fathers and their offspring. The standard deviations were high (Table 2) and an approximate dispersion of the results was observed in both populations studied.

\subsection{Quality of Pedigree Data}

The quality of the information of the ABPSL studbook based on average pedigree completeness (Fig. 2) was close to zero from the 15th (oldest) to the 11th generation in both populations and in the three most recent generations (1st, $2 \mathrm{nd}$, and $3 \mathrm{rd}$ ), with pedigree completeness of 97.7\%, 95.4\%, and 92.2\% in TP, respectively, and of $99.8 \%, 99.5 \%$, and $98.2 \%$ in RP. The number of GE was $5.7 \pm 1.4$ and $6.4 \pm 0.7$ for TP and RP, respectively.

\subsection{Parameters Related to the Inbreeding Coefficient}

There were 14 matings between full-sibs, 607 between half-sibs, and 149 between parents and offspring. The $\mathrm{F}$ value was $4.06 \% \pm$ $4.94 \%$ in $\mathrm{TP}$, and a slight increase of $0.40 \%-4.46 \% \pm 4.34 \%$ was

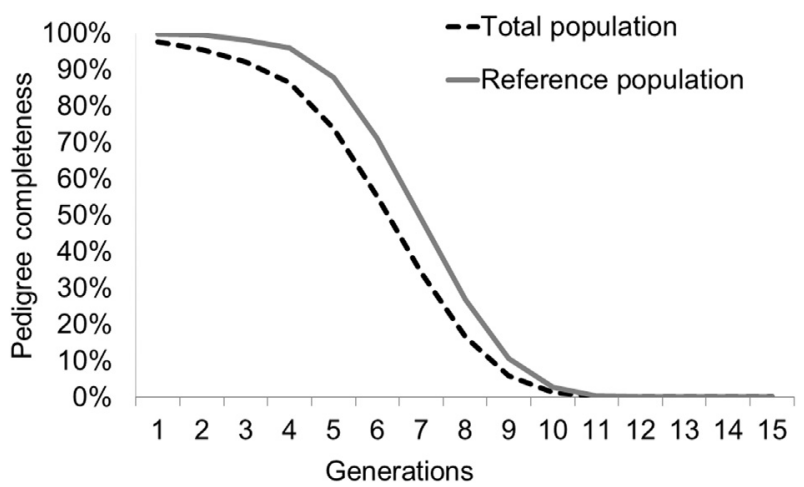

Fig. 2. Completeness of pedigree information per generation for both populations (total and reference) of Lusitano horses in Brazil (15th generation of older animals). observed in RP. The AR coefficient was $5.41 \% \pm 1.69 \%$ in TP and increased by $0.56 \%-5.97 \% \pm 1.20 \%$ in RP. The $\Delta \mathrm{F}$ per generation was $0.96 \% \pm 2.09 \%$ in TP, while a lower value $(0.85 \% \pm 0.90 \%)$ was observed in RP (Table 3 ). The percentage of animals with $\mathrm{F}$ different from zero was $88.7 \%$ in TP and $98.0 \%$ in RP (Table 3). Only two noninbred animals were born in the last year evaluated (2012).

The $\mathrm{N}_{\mathrm{e}}$ obtained based on $\Delta \mathrm{F}$ is the most common parameter in the literature and was 89 and 90 in TP and RP, respectively. Using the individual increase in inbreeding, $\mathrm{N}_{\mathrm{e}}$ values of 52 (TP) and 59 (RP) were obtained.

\subsection{Probability of Gene Origin and Genetic Drift}

The genetic variability of the populations demonstrated by the probability of gene origin (Table 3 ) indicated an effective number of founders $\left(f_{e}\right)$ of 33 , ancestors $\left(f_{a}\right)$ of 30 , and founder genomes $\left(f_{g}\right)$ of 19 in TP. These values decreased to 29,26 , and 15 , respectively, in RP.

Analysis of possible genetic drift in the populations showed an $\mathrm{f}_{\mathrm{e}} / \mathrm{N}_{\mathrm{e}}$ ratio of 0.64 in TP and of 0.49 in RP (Table 3). When the absence of bottleneck effects was evaluated, $\mathrm{f}_{\mathrm{e}} / \mathrm{f}_{\mathrm{a}}$ ratios of 1.10 (TP) and $1.12(\mathrm{RP})$ were obtained. The $\mathrm{f}_{\mathrm{e}} \sim\left(\mathrm{N}_{\mathrm{e}} / 2\right)$ values were $33-26$ and 29-30 for TP and RP, respectively.

\subsection{Genetic Conservation Index}

The GCI indicated a mean number of founders per individual of $9.6 \pm 2.9$ and $9.7 \pm 2.9$ in TP and RP, respectively, with a maximum GCI of 22.1 founders. In RP, GCI values less than 7.7 and higher than 11.7 corresponded to the 25 th and 75 th percentiles, respectively.

\subsection{Genetic Contributions}

The total number of founders (Table 3) of the Lusitano breed in Brazil represents $2.7 \%$ (TP) and 5.4\% (RP) of each population and the total number of ancestors $2.3 \%$ (TP) and $4.1 \%$ (RP). The cumulative genetic contribution (Table 3 ) of the 10,50 , and 100 most influential founders exhibited a reduced increase in RP by $0.8 \%, 3.9 \%$, and $3.0 \%$, respectively, compared with TP. The cumulative marginal genetic contributions of ancestors were also slightly increased in RP by $5.4 \%, 2.6 \%$, and $1.4 \%$ for the 10,50 , and 100 major ancestors (Table 3).

Fig. 3 shows the genetic contributions of the 10 most influential founders of the Lusitano Breed in Brazil since the first birth registered (1967) until 2012, which are Agareno, Destinado IV, Príncipe VIII, Primoroso, Cartujano, Jamonero III, Innato, Mejicano, Habanero VIII, and Carocha III.

The marginal genetic contributions of the 15 most influential ancestors, founders or not, responsible for the presence of the breed in Brazil are shown in Table 4 for TP and RP. The ancestors that increased their marginal contributions in RP were Agareno, Príncipe VIII, Afiançado de Flandes, Estribilho, Whisky, Bailador, Quimono, and Sultão I. Ancestors Cartujano and Viscaina were replaced in RP by Hucharia and Guizo.

\section{Discussion}

\subsection{Data Analysis and Distribution of Birth Records}

In $\mathrm{RP}$, only $0.2 \%$ of the animals were imported, indicating the sustainability of Brazilian breeding. These findings show that animals born in Brazil have the capacity to influence the future of the Lusitano breed in the world, with the possibility of Brazilian breeders becoming an exporter of Lusitano horses. 
Table 3

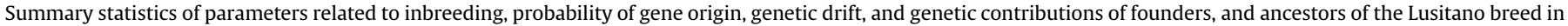
Brazil.

\begin{tabular}{|c|c|c|}
\hline Item & Total Population & Reference Population \\
\hline \multicolumn{3}{|l|}{ Parameters related to inbreeding } \\
\hline Average inbreeding coefficient ${ }^{\mathrm{a}}, \mathrm{F}(\%)$ & $4.06 \pm 4.94$ & $4.46 \pm 4.34$ \\
\hline Average related coefficient, AR (\%) & $5.41 \pm 1.69$ & $5.97 \pm 1.20$ \\
\hline Increase in inbreeding ${ }^{\mathrm{a}}, \Delta \mathrm{F}(\%)$ & $0.96 \pm 2.09$ & $0.85 \pm 0.90$ \\
\hline Effective population size ${ }^{b}, N_{e}(n)$ & 89 & 90 \\
\hline Effective population size ${ }^{c}, N_{e}(n)$ & 52 & 59 \\
\hline Number of animals with inbreeding coefficient different from zero (n) & 16,777 & 8,160 \\
\hline \multicolumn{3}{|l|}{ Probability of gene origin } \\
\hline Effective number of founders, $f_{e}(n)$ & 33 & 29 \\
\hline Effective number of ancestors, $f_{a}(n)$ & 30 & 26 \\
\hline Effective number of founder genomes, $f_{g}(n)$ & 19 & 15 \\
\hline \multicolumn{3}{|l|}{ Genetic drift } \\
\hline $\mathrm{f}_{\mathrm{e}} / \mathrm{N}_{\mathrm{e}}^{\mathrm{c}}$ & 0.64 & 0.49 \\
\hline $\mathrm{f}_{\mathrm{e}} / \mathrm{f}_{\mathrm{a}}$ & 1.10 & 1.12 \\
\hline $\mathrm{f}_{\mathrm{e}} \sim\left(\mathrm{N}_{\mathrm{e}} / 2\right)^{\mathrm{c}}$ & $33-26$ & $29-30$ \\
\hline \multicolumn{3}{|l|}{ Contributions of founders and ancestors } \\
\hline Total number of animals per population & $18,922^{\mathrm{d}}$ & $8,329^{\mathrm{d}}$ \\
\hline Total number of animals with both parents known (n) & $18,406^{\mathrm{e}}$ & $8,315^{\mathrm{e}}$ \\
\hline Number of founders (n) & 516 & 453 \\
\hline Genetic contributions of the 10 most influential founders (\%) & 42.7 & 43.5 \\
\hline Genetic contributions of the 50 most influential founders (\%) & 74.3 & 78.2 \\
\hline Genetic contributions of the 100 most influential founders (\%) & 85.7 & 88.7 \\
\hline Number of ancestors (n) & 427 & 341 \\
\hline Genetic contributions ${ }^{\mathrm{f}}$ of the 10 most influential ancestors (\%) & 46.8 & 52.2 \\
\hline Genetic contributions ${ }^{\mathrm{f}}$ of the 50 most influential ancestors (\%) & 82.0 & 84.6 \\
\hline Genetic contributions ${ }^{\mathrm{f}}$ of the 100 most influential ancestors (\%) & 91.7 & 93.1 \\
\hline
\end{tabular}

a All animals in the population studied.

b According to Falconer and Mackay (1996).

c According to Gutiérrez et al. (2009).

d Total animal studies in each population.

e Total of animals with known father and mother in each population.

f Marginal genetic contributions.

Similar onsets of birth records have been reported in the literature for the Brazilian Campolina [17] and Mangalarga Marchador [31] horse breeds. A decline in the registration of births was observed in the 1990s for the Brazilian horse breeds Mangalarga [16], Campolina [17], Brazilian Sport Horse [18], and Mangalarga Marchador [31]. According to the last authors, the reduction in the number of registered births can be explained by the implementation of the economic plan of the Brazilian government that resulted in a cause-effect relationship due to the oscillations in the Brazilian economy. By contrast, the annual number of registered births increased in the Lusitano breed during this period (1990s) (Fig. 1), possibly because it is not a native Brazilian breed and was in a phase of importation and expansion in the country during that phase.

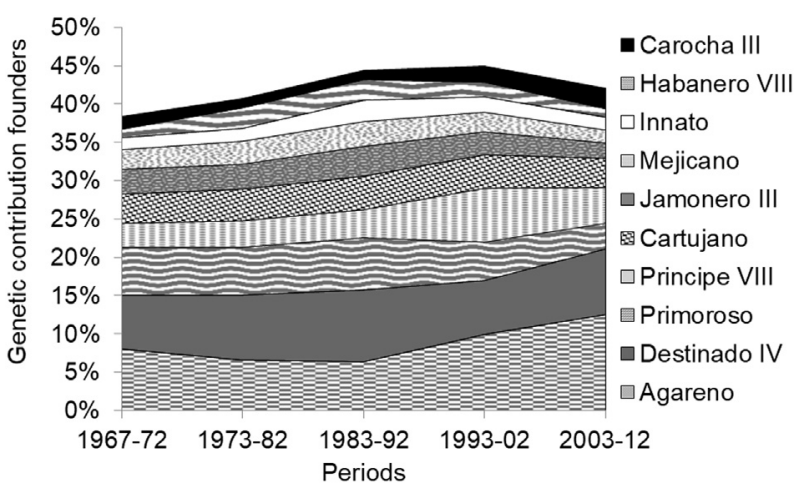

Fig. 3. Evolution of the genetic contribution of the 10 most influential founders of the Lusitano breed in Brazil from the first record in 1967-2012, during five different periods.
According to the Anualpec yearbook [32], the number of horses decreased between 2002 and 2009 in Brazil, with a reduction of 278,375 births, while the number of Lusitano horses was stable during this period. The decline that started in 2010 (Fig. 1) was the result of the serious economic-financial crisis in Europe and the United States, which caused a deceleration in horse breeding after 2008 in various parts of the world. A similar trend has been described in studies on the Lusitano [2], Old Kladruber [14], and Pantaneiro [15] breeds. The Lusitano breed in Brazil exhibited resistance to the decrease in equine records more than once, but the downward trend that started in 2010 (Fig. 1) has become a matter of concern for the evolution of the breed. However, it is possible that some of the animals born in 2012 had not yet appeared in the database when it was consulted for the present study.

The importance of the month of birth is related to the fact that July is considered the ideal month for the birth of sporting animals in the southern hemisphere. Competitions start in July, that is, animals born in this month have a competitive advantage over animals born in subsequent months because they are older and therefore exhibit greater physiological and sport development. This applies particularly to the classes of younger animals. Studies involving animals born in the southern hemisphere indicated the same trend observed for Lusitano horses registered in Brazil for the Mangalarga Marchador breed [31], with a concentration of birth (>85\%) between September and March. In the Mangalarga breed [16], a peak was found in November (17.4\%) and a higher concentration between September and January (78.5\%). A better but far from desired distribution was observed in Thoroughbreds [33], with $20.2 \%$ of births in the ideal month (July) and a larger number of births in August (24.1\%), followed by September (23.0\%). The 
Table 4

Marginal genetic contributions (in \%) of the 15 most influential ancestors (founders or not) to the Lusitano breed in Brazil.

\begin{tabular}{|c|c|c|c|c|c|}
\hline No. & Name & Year of Birth & Sex & Breeder & Marginal Contribution (\%) \\
\hline \multicolumn{6}{|c|}{ Total population } \\
\hline 1 & Agareno & 1931 & $\mathrm{~S}$ & Manuel Tavares Veiga & 10.62 \\
\hline 2 & Príncipe VIII & 1943 & $\mathrm{~S}$ & D. Francisco C Navarro & 7.12 \\
\hline 3 & Destinado IV & 1940 & $\mathrm{~S}$ & D. Francisco C Navarro & 6.35 \\
\hline 4 & Primoroso & 1927 & $\mathrm{~S}$ & Hermanos Dominguez & 4.61 \\
\hline 5 & Cartujano & 1928 & $\mathrm{~S}$ & D. António Perez Tinao & 4.09 \\
\hline 6 & Bailador & 1962 & $\mathrm{~S}$ & Manuel Tavares Veiga & 3.20 \\
\hline 7 & Estribilho & 1963 & $\mathrm{~S}$ & M Assunção Coimbra & 2.85 \\
\hline 8 & Jamonero III & 1953 & $\mathrm{~S}$ & D. Isabel M V Terry & 2.70 \\
\hline 9 & Viscaina & 1933 & M & D. M Romero Benitez & 2.64 \\
\hline 10 & Afiançado de Flandes & 1982 & $\mathrm{~S}$ & Quinta de Flandes & 2.60 \\
\hline 11 & Whisky & 1947 & M & F Sommer D'Andrade & 2.38 \\
\hline 12 & Babel & 1965 & $\mathrm{~S}$ & L J Ortigão Costa & 2.32 \\
\hline 13 & Quimono & 1974 & $\mathrm{~S}$ & A J Fonseca Alcobia & 2.23 \\
\hline 14 & Innato & 1962 & $\mathrm{~S}$ & D. J Domeq de La Riva & 1.94 \\
\hline 15 & Sultão I & 1942 & $\mathrm{~S}$ & Manuel Tavares Veiga & 1.78 \\
\hline All 15 & & & & & 57.45 \\
\hline \multicolumn{6}{|c|}{ Reference population } \\
\hline 1 & Agareno & 1931 & $\mathrm{~S}$ & Manuel Tavares Veiga & 12.48 \\
\hline 2 & Principe VIII & 1943 & $\mathrm{~S}$ & D. Francisco C Navarro & 8.58 \\
\hline 3 & Destinado IV & 1940 & $\mathrm{~S}$ & D. Francisco C Navarro & 4.73 \\
\hline 4 & Afiançado de Flandes & 1982 & $\mathrm{~S}$ & Quinta de Flandes & 4.20 \\
\hline 5 & Estribilho & 1963 & $\mathrm{~S}$ & M. Assunção Coimbra & 3.85 \\
\hline 6 & Whisky & 1947 & M & F Sommer D'Andrade & 3.84 \\
\hline 7 & Bailador & 1962 & $\mathrm{~S}$ & Manuel Tavares Veiga & 3.44 \\
\hline 8 & Primoroso & 1927 & $\mathrm{~S}$ & Hermanos Dominguez & 3.33 \\
\hline 9 & Quimono & 1974 & $\mathrm{~S}$ & A J Fonseca Alcobia & 2.95 \\
\hline 10 & Hucharia & 1943 & M & Estado Português CN & 2.74 \\
\hline 11 & Babel & 1965 & $\mathrm{~S}$ & L J Ortigão Costa & 2.04 \\
\hline 12 & Sultão I & 1942 & $\mathrm{~S}$ & Manuel Tavares Veiga & 2.04 \\
\hline 13 & Jamonero III & 1953 & $\mathrm{~S}$ & D. Isabel M, V Terry & 2.00 \\
\hline 14 & Innato & 1962 & $\mathrm{~S}$ & D. J Domeq de La Riva & 1.69 \\
\hline 15 & Guizo & 1947 & $\mathrm{~S}$ & Manuel Tavares Veiga & 1.69 \\
\hline All 15 & & & & & 59.87 \\
\hline
\end{tabular}

Abbreviations: M, mare; No., number; S, stallion.

distribution of births over the year in Brazil can be explained by the abundance of feed (pastures) throughout all quarters of the year and by the higher nutritional value in the last quarter (spring), a fact that leads Brazilian breeders to opt for the quality of their pastures at the expense of the ideal month. Because the Lusitano horse is mainly a sporting animal, the best choice is that a larger number of births should occur in the third quarter of the year. To help comparing the results and their discussion with several different horse breeds, a supplementary table can be consulted online (Supplementary material-Table A).

\subsection{Reproductive Parameters and Generation Interval}

The differentiated values of breeding animals that left descendants (progenies) by national and imported origins are also observed in the literature. In the study of Cervantes et al [12] on Spanish Arab horses, the contribution of imported individuals was high, corresponding to $47.9 \%$ of all descendants of the breed's studbook. Koenen et al [34], providing an overview of the breeding objectives for sport horses, reported percentages of mares covered by an imported stallion of $74 \%$ for Danish Warmblood, $62 \%$ for Swedish Warmblood, 32\% for Irish Horse Board, 31\% for Royal Dutch Sport Horse, and $6 \%$ for Selle Français. The percentage of use of imported Lusitano breeding animals among those imported to Brazil can be explained by the choices of breeders who purchased these animals from foreign populations mainly for breeding, with dams being used almost exclusively for this purpose. Despite the greater utilization within the origin of imported animals, the percentage of offspring with Lusitano parents born in Brazil was higher, demonstrating the reproductive sustainability on the American continent of the responsibility of Brazilian horse farms.

The percentages of breeding animals that left descendants are 3.3\% (stallions) and 22.6\% (mares) for the Mangalarga Marchador breed [31], and $8.3 \%$ (stallions) and $22.2 \%$ (mares) for the world Lusitano population [3]. These values are lower than those obtained in the present study, indicating greater utilization of breeding animals in the formation of the Lusitano population in Brazil and consequent higher genetic diversity. The smaller number of stallions in all studies reported may be due in part to the greater difficulty of approval in the studbook and their reproductive superiority, in which a single stallion can have dozens of offspring while a natural limit exists for mares. The low breeding stallion-tomare ratio reduces the intensity of selection, which may result in less genetic progress of the population [35].

For the world Lusitano population, Vicente et al [2] indicated that the ratio of 5 mares per sire (lower than in the present study) impairs selection of the Lusitano breed. The small number of mares per stallions observed in the present study, similar to Quarter Horse in Brazil [19], should be taken into consideration by the association and by breeders, which can be modified and improved, increasing genetic progress to the levels (mares per stallion) of other breeds such as Thoroughbreds in New Zealand (43-1) [36] and Hanoverians $(45-1)$ [11].

Vicente et al [2] reported mean numbers of offspring similar to those of the present study (Table 1) for the Lusitano breed, with a mean number of offspring of 13.1 for stallions and of 4.0 for mares, suggesting identical reproductive guidelines on Brazilian horse farms and in the remaining countries where Lusitanos are reared. The numbers of offspring observed in the literature were different 
(stallions) and similar (mares) compared with those of the Lusitano population in Brazil (Table 1), with 22.2 (stallions) and 3.1 (mares) offspring for the Campolina breed [17],10.7 (stallions) and 3.7 (mares) offspring for the Quarter Horse [19], and 23.8 (stallions) and 4.4 (mares) offspring for the Mangalarga breed [16]. Reproductive inequalities between sexes in horses can be seen in all breeds (Supplementary material-Table A), indicating greater participation of dams in the maintenance of the genetic diversity of each breed.

The age at birth of the first foal indicates the onset of reproductive life and, considering that horses are able to breed at 2 years of age [37], this did not influence the age at first foal since horses exhibit a late mean age at birth of their first progeny $[2,38]$. The main causes of this event as reported in various studies include differences in reproductive strategies between breeds and farms (high standard deviations in the results of Table 1), after functional performance and credits established in their sports career. Another factor is the regulations of the associations, which only permit the registry of animals in the studbook at certain ages and riding classes, a fact resulting in the approval of animals at older ages. Other factors include hormonal disorders, genital and parasite infections, and inadequate management practices before the breeding season, interfering with the onset of reproductive life of horses. An almost identical mean age at first progeny (Table 1) was reported for stallions of the world Lusitano population [2], with a difference of only 0.3 years. The delay in the age at first progeny in the Lusitano breed may be explained by the regulations of their association, which only permit the application of stallions after 4 years of age and of recommended or merit stallions (animals recommended by APSL for breeding can have an unlimited number of offspring) at a minimum age of 6 years. Many breeders who wish their mares covered by these stallions wait to perform matings or use the semen of these animals, consequently increasing the age at birth of the first foal. However, the mean age of mares (Table 1) of the present study was not far from the ideal proposed by Davies Morel et al [39]. These authors described the ideal age of mares to start breeding to be between 5 and 6 years, a period when they will have reached the final mature size.

The age at birth of the last progeny (Table 1) was similar to that reported by Vicente et al [2], who estimated a mean age of 10.5 years for sires and dams. The end of reproductive life of horses has been little studied and the age at last progeny is less reported than the age at first progeny. Further studies are necessary to understand the reasons for at age last progeny.

The coefficients of variation for all reproductive parameter indicate high dispersion of the results among animals, which was greater in stallions for all parameters, demonstrating an imbalance in the utilization of males and females. The results suggest different objectives within the Lusitano breed in Brazil, with the observation of sires and dams with a small or large number of offspring, late age at first progeny, and a reduced mean number of dams per sire. The values observed are common among some equine breeds, but are in contrast to the balanced values of cattle for which studies have already determined, for example, the ideal number of cows per bull [40].

Scientific studies have not shown the same influence on horse breeds as studies involving other livestock species (e.g., cattle, pigs, and small ruminants). The difficulty in designing the same experiments is mainly due to the peculiarities of horses and to the fact that, unlike in the case of other livestock species, the access of the scientific community to horse farms is limited, impairing the approximation between researchers and breeders. Breeders of the Lusitano horse in Brazil should increase and balance the number of dams per sire (genetic evolution), begin the reproductive life of animals earlier (decrease in GI), and collaborate more actively with researchers to establish new selection programs, which would permit to observe reproductive parameters that contribute to the genetic evolution of horses as observed for other livestock species.

Vicente et al [2], evaluating Lusitano horses using data collected throughout the world, obtained a GI that was similar to (TP) and the same as (RP) that of Lusitano in Brazil, indicating a possible influence of animals born in Brazil on the values of the world population. Although long, the GI is similar for all breeds in Brazil, such as Mangalarga (9.5 years) [16], Campolina (8.7 years) [17], Brazilian Sport Horse (10.8) [18], and Quarter Horse (9.6 years) [19]. The GI obtained in Europe for Andalusian (10.1 years) [8], Holstein (10.3 years) [9], and Old Kladruber (11.3 years) [14] was the same as those estimated for the Lusitano horse (Supplementary material-Table A). A long GI is the result of different factors such as the late selection of stallions and mares and long reproductive life. Consequently, because the GI is present in the denominator of the formula used to calculate genetic gain, it will act inversely proportional, reducing the expected response to selection. The reduction in genetic gain due to a long GI in the Lusitano breed is supported by the high standard deviations, indicating that some breeders are concerned about the GI of their populations, while a large number of breeders who are not concerned are responsible for decelerating the evolution of the Lusitano breed in Brazil.

\subsection{Quality of Pedigree Data}

The mean values of pedigree completeness (Fig. 2) tended to increase over time and the loss of data was lower when compared with a study on Spanish Arab horses [12], which reported percentages of $92.0 \%, 86.6 \%$, and $80.8 \%$ for the three most recent generations. For Lipizzan [40] and Old Kladruber [14], the authors indicated high values of completeness around $100 \%$ for the last five and six generations, respectively. In the study of the world Lusitano population, the percentages of pedigree completeness obtained for the whole population of $98.8 \%, 97.8 \%$, and $97.1 \%$ [2] indicate that the APSL data are slightly more complete than the whole data of ABPSL, with more in-depth pedigree knowledge. The estimation of pedigree completeness is important because the parameters related to the inbreeding coefficient, probability of gene origin, and genetic drift of a given individual depend on how much of his ancestry is known. The moderate values of the present study can be improved, the greater this knowledge, the more reliable will be the estimated values in relation to the base population studied.

When compared with the literature, the number of GE (5.7 in $\mathrm{RP})$ can be considered low, but was higher than that reported in studies on Pantaneiro (0.7 GE) [15], Brazilian Sport Horse (1.7 GE) [18], Paint Horse (4.8 GE) [10], Quarter Horse (5.1) [19], and equal to Holstein (5.6 GE) [9]. However, the GE was lower than in Purebred Lusitano (9.9 GE) [2] and Old Kladruber (15.1 GE) [14]. Similar to the literature (Supplementary material-Table A), the increase in the amount of pedigree data in RP indicates improvement in the quality of pedigree information in the studbook of ABPSL. However, we must always analyze and compare these results with care because they depend on the quality and degree of completion of the pedigrees, so the values obtained for GE may have a direct influence on inbreeding, $\mathrm{f}_{\mathrm{e}}$ and $\mathrm{f}_{\mathrm{a}}$ estimates.

\subsection{Parameters Related to the Inbreeding Coefficient}

The main effect of $\mathrm{F}$ (Table 3 ) is an increase in homozygosity as a result of more closely related animals. A higher inbreeding coefficient (9.4\%) has been reported by Vicente et al [2] for the whole population of Lusitano horses registered in the world when a period of 5 years (2005-2009) was analyzed. An even higher value (11.3\%) was obtained by the authors for an RP. An F of $4.6 \%$ was 
observed exclusively for Lusitano born in Brazil and for the same period (2005-2009). Considering the values reported by Vicente et al [2], Lusitano horses born in Brazil contribute to an overall decrease of inbreeding in the breed. This fact may indicate that farms have been introducing different lineages of less related Lusitano horses in Brazil over the years. On the other hand, this reduction in the inbreeding coefficient of animals reared in Brazil may also be explained in part by the lower level of pedigree knowledge compared with the Lusitano studbook of APSL. The maintenance of a low level of inbreeding in Brazilian Lusitano horses may contribute in the future to the export of breeding animals to reduce inbreeding on Lusitano horse farms around the world. Other authors reported higher value of $\mathrm{F}$ for Andalusian (8.5\%) [8], Lipizzaner (10.8\%) [13], and Old Kladruber (13.0\%) [14]. Low levels of $\mathrm{F}$ are observed for Brazilian breeds, including Campolina (1.3\%) [17], Brazilian Sport Horse (0.24\%) [18], and Mangalarga Marchador (5.7\%) [31] (Supplementary material-Table A). Low levels of $\mathrm{F}$ are an indicator that the breeds are organized in an open studbook system, which permits the utilization of sires and dams from other breeds with a consequent reduction in inbreeding.

$\Delta \mathrm{F}$ was reduced (Table 3 ), with a small decrease in $\mathrm{RP}$, despite the observation of a larger number of mating among related animals compared with TP. An increase in consanguinity was observed among annual births, finishing 2012 with $99.5 \%$ of births of related animals. The standard deviations obtained (Table 3) are not of major concern because they remained within acceptable levels for inbreeding parameters. High standard deviations were also observed in the study of Vicente et al [2]. Despite the lower dispersions in the present study, the results should not be overlooked because the small number of Lusitano horses compared with other breeds or species may, at any time, change the $\mathrm{F}$ values to less desired levels.

Values of $\mathrm{N}_{\mathrm{e}}$ have been reported for Hanoverian (372) [11], Spanish Sport Horse (226) [41], Brazilian Sport Horse (223) [18], Holstein (55) [9], and Old Kladruber (53) [14] breeds. Studies that obtained high values of $\mathrm{N}_{\mathrm{e}}$ suggest, by definition, reduced inbreeding levels because of the direct relationship between $\mathrm{N}_{\mathrm{e}}$ and inbreeding rate [24]. This is obviously also related to the fact that most of these breeds have open studbooks, thus permitting the introduction of new genes and a consequent reduction in inbreeding. The small increase of $\mathrm{N}_{\mathrm{e}}$ in RP (Table 3 ) is related to the fact that the increase in inbreeding was lower in the last generation, and possibly to the introduction of new lineages and different utilizations of major ancestors, either founders or not (Fig. 3; Table 4). However, and according to Caballero and Toro [42], the comparison of different $\mathrm{N}_{\mathrm{e}}$ values is problematic because the true value is unknown and the $\mathrm{N}_{\mathrm{e}}$ obtained depends in part on the effect of changes in mating policies (level of inbred animals).

For the world Lusitano population, Vicente et al [2] reported that the $\mathrm{N}_{\mathrm{e}}$ of 41 obtained for a period of 5 years (2005-2009) is a matter of concern for the maintenance of genetic diversity. The $\mathrm{Ne}_{\mathrm{e}}$ observed in the present study for the same period and using the same method as those authors (individual increase in inbreeding) was 57. Considering the minimum $\mathrm{N}_{\mathrm{e}}$ (50) recommended by the FAO [43], the value obtained in this study is less worrisome for the maintenance of genetic diversity, and Lusitano horses born in Brazil may therefore assist in maintaining the diversity of the world population.

\subsection{Probability of Gene Origin and Genetic Drift}

Lower probabilities of gene origin are reported in the literature for the Lusitano breeds ( $f_{e}$ of $28, f_{a}$ of 12 , and $f_{g}$ of 6 ) [2], Holstein $\left(f_{e}\right.$ of $50, f_{a}$ of 29 , and $f_{g}$ of 17) [9], and Old Kladruber $\left(f_{e}\right.$ of $93, f_{a}$ of 17 , and $f_{g}$ of 5) [14] and, whereas higher values were found for Paint
Horse $\left(f_{e}\right.$ of $561, f_{a}$ of 208 , and $f_{g}$ of 139 ) [10], Brazilian Sport Horse ( $f_{e}$ of $466, f_{a}$ of 274 , and $f_{g}$ of 224$)$ [18], Quarter Horse $\left(f_{e}\right.$ of $1,045, f_{a}$ of 156, and $f_{g}$ of 105) [19] and Spanish Sport Horse ( $f_{e}$ of $963, f_{a}$ of 407, and $f_{g}$ of 254) [41] (Supplementary material-Table A). Higher values suggest the use of a larger number of animals in the formation of the breeds. The genetic variability of breeds observed in the literature, as demonstrated by the results of the probability of gene origin, is a matter of concern in horse breeding. However, the variation in the three parameters of gene origin probability obtained in the present study was lower than that described in the literature. The effective number of founders in both populations, comparing the number of founders (Table 3), indicates the preferential use of certain lineages of founders. Because each population has its own characteristics, comparison with the literature should be done with caution and within each breed, considering the three parameters for each population.

Genetic drift is approaching stability in the Brazilian Lusitano breed (Table 3), with a progressive increase in the representation of founders $[28,29]$ in RP as indicated by $\mathrm{f}_{\mathrm{e}} / \mathrm{N}_{\mathrm{e}}>0.5$ and $\mathrm{f}_{\mathrm{e}} \sim\left(\mathrm{N}_{\mathrm{e}} / 2\right)$, which are close to the desired. The $\mathrm{f}_{\mathrm{e}} / \mathrm{f}_{\mathrm{a}}$ ratio (Table 3 ) confirms the absence of worrisome bottleneck effects in the population despite the increase of 0.02 in RP. Different results are observed in the literature, with the loss of genetic variability due to the utilization of lineages with a reduced number of founders and worrisome bottleneck effects; for example, $\mathrm{f}_{\mathrm{e}} / \mathrm{f}_{\mathrm{a}}$ ratios of 1.69 for the Brazilian Sport Horse [18], 1.72 for the Holstein [9], 2.34 for Lusitano using world data [2], 2.37 for the Spanish Sport Horse [41], 2.70 for the Paint Horse [10], 5.47 for the Old Kladruber [14], and 6.70 for Quarter Horse [19].

The persistence of the founder lines is observed in several breeds throughout the world, being lower in the present study. It should be noted that the values of each breed may vary due to different qualities of studbook data information (pedigree completeness and GE).

\subsection{Genetic Conservation Index}

In the literature, mean GCIs of 1.3, 9.5 and 14.8 and maximum values of 7.2, 19.2 and 31.2 have been reported for the Pantaneiro [15] Lusitano [2] and Quarter Horse [19] breeds, respectively (Supplementary material-Table A). The small differences between the world Lusitano population and the present study are visible in the maximum values and are explained by the heterogeneous importation of genetic lineages of Lusitano into Brazil. Consequently, different sires and dams were used over time, which resulted in slightly higher $\mathrm{GCI}$ values.

Animals with higher indexes exhibit greater conservation, that is, a greater balance in the number of founders, and should be used (preferentially in the choice of breeding animals) in genetic selection programs to maintain the genes transmitted by founders [30]. Brazilian farms are a good choice for breeding animals of the Lusitano breed or of world breeds with origin in the Lusitano horse, with the Mangalarga Marchador, Campolina, Andaluz Brasileiro or Iberian breeds (e.g., Portuguese and Spanish Sport Horses), to introduce founder genes of the Lusitano breed.

\subsection{Genetic Contributions}

A slight increase in the genetic contributions explained by the 10,50 , and 100 most influential founders was observed from TP to RP (Table 3), indicating a similar use of lineages as the major founders in RP. This change contributed to maintaining the genetic diversity of the Lusitano breed in Brazil over the last 10 years (2003-2012) evaluated. The marginal genetic contributions of ancestors, with a small increase in RP (Table 3), suggest that 
ancestors contributed equally in TP and RP, demonstrating the maintenance of alleles of ancestral sires and dams in the last generation.

The marginal genetic contribution of the 15 most influential ancestors in the present study (Table 4) was higher than that reported for Hanoverians (34.9\%) [11]. Considering the 10 most influential ancestors with the greatest marginal genetic contributions to the world Lusitano population reported in the study of Vicente et al [2], half of these animals were also ancestors of the Brazilian population (Table 4), represented by Agareno, Príncipe VIII, Destinado IV, Primoroso, and Cartujano at different proportions and maintaining only the order of the marginal genetic contribution of the most influential ancestor (Agareno). Although these authors studied the same breed as in the present study, the data used refer to the period from 2005 to 2009, with a much larger sample of data and the approaches taking place in different populations. Consequently, the observation of differences in the parameters between the two studies was expected.

In the study on the world Lusitano population [2], the number of founders was 14 and 99 , corresponding to $50 \%$ and $90 \%$ of the genetic contribution of founders, respectively. The Brazilian Lusitano population exhibited variations in founder lineages (Fig. 3) and, consequently, greater genetic diversity of the animals born on Brazilian farms. These differences may help explain the lower inbreeding and greater genetic diversity of Lusitano horses born in Brazil.

\section{Conclusion}

The inbreeding and relatedness coefficients demonstrate some control on the part of Brazilian breeders, suggesting that Lusitano horses born in Brazil can be introduced as breeding animals in the world Lusitano population to increase the genetic diversity of the breed. The long GI obtained indicates a delay in annual genetic gain and the lack of speedy decision-making about the appropriate use of sires and dams. Although the absence of bottleneck effects is evident and positive, the low probabilities of gene origin and the high genetic contribution of a small number of animals suggest that Brazilian breeders need to monitor the genetic diversity of the Lusitano horse in next generations through breeding programs.

\section{Acknowledgments}

The authors thank the Associação Brasileira de Criadores do Cavalo Puro-Sangue Lusitano (ABPSL) for providing the data used in this study. They are also grateful to the anonymous reviewers for their helpful comments. The authors acknowledge the invaluable contribution of the late Professor Dr Marcílio Dias Silveira da Mota.

\section{Financial Disclosure}

Productivity grant attributed to Professor Dr J. Augusto II, by Conselho Nacional de Desenvolvimento Científico e Tecnológico (CNPq-Brazil).

\section{Supplementary Data}

Supplementary data related to this article can be found at https://doi.org/10.1016/j.jevs.2018.07.009.

\section{References}

[1] Luís C, Cothran EG, Oom MDM. Inbreeding and genetic structure in the endangered Sorraia horse breed: Implications for its conservation and management. J Hered 2007;98:232-7.
[2] Vicente AA, Carolino N, Gama LT. Genetic diversity in the Lusitano horse breed assessed by pedigree analysis. Livest Sci 2012;148:16-25.

[3] Vicente AA, Carolino N, Gama LT. Demographic parameters in Lusitano horse. Arch Zootec 2009;58:501-4.

[4] MacCluer JW, Boyce AJ, Dyke B, Weitkamp LR, Pfenning DW, Parsons CJ. Inbreeding and pedigree structure in Standardbred horses. J Hered 1983;74: 394-9.

[5] Wright S. Evolution in Mendelian populations. Genetics 1931;16:97-159.

[6] Boichard D, Maignel L, Verrier É. The value of using probabilities of gene origin to measure genetic variability in a population. Genet Sel Evol 1997;29:5-23.

[7] Maignel L, Boichard D, Verrier E. Genetic variability of French dairy breeds estimated from pedigree Infonnation. Interbull Bull 1996;14:48-56.

[8] Valera M, Molina A, Gutiérrez JP, Gómez J, Goyache F. Pedigree analysis in the Andalusian horse: population structure, genetic variability and influence of the Carthusian strain. Livest Prod Sci 2005;95:57-66.

[9] Roos L, Hinrichs D, Nissen T, Krieter J. Investigations into genetic variability in Holstein horse breed using pedigree data. Livest Sci 2015;177:25-32.

[10] Siderits M, Baumung R, Fuerst-Waltl B. Pedigree analysis in the German Paint Horse: genetic variability and the influence of pedigree quality. Livest Sci 2013;151:152-7.

[11] Hamann H, Distl O. Genetic variability in Hanoverian warmblood horses using pedigree analysis. J Anim Sci 2008;86:1503-13.

[12] Cervantes I, Molina A, Goyache F, Gutiérrez JP, Valera M. Population history and genetic variability in the Spanish Arab Horse assessed via pedigree analysis. Livest Sci 2008;113:24-33.

[13] Zechner P, Sölkner J, Bodó I, Druml T, Baumung R, Achmann R, et al. Analysis of diversity and population structure in the Lipizzan horse breed based on pedigree information. Livest Prod Sci 2002;77:137-46.

[14] Vostrá-Vydrová H, Vostrý L, Hofmanová B, Krupa E, Zavadilová L. Pedigree analysis of the endangered Old Kladruber horse population. Livest Sci 2016;185:17-23.

[15] McManus C, Santos SA, Lima Dallago BS, Paiva SR, Saraiva Martins RF, Neto JB, et al. Evaluation of conservation program for the pantaneiro horse in Brazil. Rev Bras Zootec 2013;42:404-13.

[16] Mota MDS, Prado RSA, Sobreiro J. Characterization of the Mangalarga horse population in Brazil. Arch Zootec 2006;55:31-7.

[17] Procópio AM, Bergmann JAG, Costa MD. Formação e demografia da raça Campolina. Arq Bras Med Vet e Zootec 2003;55:361-5.

[18] Medeiros BR, Bertoli CD, Garbade P, McManus CM. Brazilian Sport Horse: pedigree analysis of the Brasileiro de Hipismo breed. Ital J Anim Sci 2014;13: 657-64.

[19] Faria RAS, Maiorano AM, Bernardes PA, Pereira GL, Silva MGB, Curi RA, et al. Assessment of pedigree information in the Quarter Horse: population, breeding and genetic diversity. Livest Sci 2018;214:135-41.

[20] SAS. SAS/STAT 9.3. Cary, NC: SAS Inst Inc; 2011.

[21] Gutiérrez JP, Goyache F. A note on ENDOG: a computer program for analysing pedigree information. J Anim Breed Genet 2005;122:172-6.

[22] James JW. Computation of genetic contributions from pedigrees. Theor Appl Genet 1972;42:272-3.

[23] The Meuwissen, Luo Z. Computing inbreeding coefficients in large populations. Genet Sel Evol 1992;24:305-13.

[24] Falconer D, Mackay T. Introduction to Quantitative Genetics. 4th Ed 1996

[25] Gutiérrez JP, Cervantes I, Goyache F. Improving the estimation of realized effective population sizes in farm animals. J Anim Breed Genet 2009;126: 327-32.

[26] Lacy RC. Analysis of founder representation in pedigrees - founder equivalents and founder genome equivalents. Zoo Biol 1989;8:111-23.

[27] Ballou JD, Lacy RC. Identifying genetically important individuals for management of genetic diversity in captive populations. In: Ballou JD, Gilpin M, Foose TJ, editors. Popul. Manag. Surviv. Recover. Anal. Methods Strateg. Small Popul. Conserv. New York: Columbia University Press; 1995. p. 76-111.

[28] Caballero A, Toro M. Interrelations between effective population size and other pedigree tools for the management of conserved populations. Genet Res 2000;75:331-43.

[29] Sørensen a C, Sørensen MK, Berg P. Inbreeding in Danish dairy cattle breeds. J Dairy Sci 2005;88:1865-72.

[30] Alderson L. A system to maximize the maintenance of genetic variability in small populations. In: Alderson L, Bodo I, editors. Genet. Conserv. Domest. Livest. Wallingford: CABI Publishing: 1992, p. 18-29.

[31] Costa MD, Bergmann JAG, Resende ASC, Fonseca CG. Análise temporal da endogamia e do tamanho efetivo da população de eqüinos da raça Mangalarga Marchador. Arq Bras Med Vet Zootec 2005;57:112-9.

[32] Informa Economics IEG|FNP. ANUALPEC 2012. http://www.anualpec.com.br/. accessed August 31, 2017.

[33] Mota MDS, Abrahão AR, Oliveira HN. Genetic and environmental parameters for racing time at different distances in Brazilian Thoroughbreds. J Anim Breed Genet 2005;122:393-9.

[34] Koenen EPC, Aldridge LI, Philipsson J. An overview of breeding objectives for warmblood sport horses. Livest Prod Sci 2004;88:77-84.

[35] Vicente AA, Carolino N, Ralão-Duarte J, Gama LT. Selection for morphology, gaits and functional traits in Lusitano horses: I. Genetic parameter estimates. Livest Sci 2014;164:1-12.

[36] Rogers CW, Gee EK, Firth EC. A cross-sectional survey of Thoroughbred stud farm management in the North Island of New Zealand. N Z Vet J 2007;55. 
[37] Langlois B. Estimation de quelques parametres demographiques du Pur Sang anglais en France. Ann Genet Sel Anim 1976;8:315-29.

[38] Mota MDS, Regitano LCA. World' s largest science, technology \& medicine open access book publisher c. RFID Technol Secur Vulnerabilities. Countermeas 2012:75-100.

[39] Davies Morel MCG, Newcombe JR, Holland SJ. Factors affecting gestation length in the Thoroughbred mare. Anim Reprod Sci 2002;74:175-85.

[40] Goddard MG, Smith C. Optimum number of bull sires in dairy cattle breeding. J Dairy Sci 1990;73:1113-22.
[41] Bartolomé E, Cervantes I, Valera M, Gutiérrez JP. Influence of foreign breeds on the genetic structure of the Spanish Sport Horse population. Livest Sci 2011;142:70-9.

[42] Cervantes I, Goyache F, Molina A, Valera M, Gutiérrez JP. Application of individual increase in inbreeding to estimate realized effective sizes from rea pedigrees. J Anim Breed Genet 2008;125:301-10.

[43] FAO. Secondary guidelines for development of national farm animal genetic resources management plans: management of small populations at risk. 1998 Roma, Italy. 